\title{
RIGHTS WITHIN OBLIGATIONS AND RESPONSIBILITIES
}

\author{
Manol STANIN \\ South-West University „Neofit Rilsky”, Blagoevgrad, Bulgaria \\ stanin@law.swu.bg
}

\begin{abstract}
The autonomous legal sphere, within which the legal measure of freedom in legal reality is manifested, has fixed borders. In this sense, the behavior, through which a right is realized, should be compliant with them. The borders are "created" by restrictions. Limiting the parameters of this behavior, and hence of freedom, is possible through the establishment of obligations. For some of these rights limits are constant, for others - they are subject to a change under certain circumstances, such as a war or another emergency circumstance, which is threatening the life of the nation.
\end{abstract}

Keywords: rights, obligations, normative system, order of magnitude, autonomous legal sphere

\section{Introduction}

The normative systems in society are a natural consequence of the need of individuals, organized into community, for stability in the presence or the absence of certain social interactions. This means that their legal regulations contain requirements, the formulation of which stems from the expectations of entities for the existence and maintenance of sustainability in the creation, amendment, termination and extinguishment the actions or inactions, covered by them. Therefore, about their incompliance there are provided unfavorable effects, intended to motivate the individuals to their observance. It confers them a characteristic of self-driving factors [1], of the effectiveness of which depends on the fulfillment of the aforementioned needs.

\section{Necessity of the existence of a system of obligations}

Law as a normative system has its own specifics. Ascertainment of rights is accompanied by establishment of a system from obligations and for their non-compliance there are various degrees of unfavorable sanctions. At first, these are State obligations to ensure the exercise of a right and to protect it from criminal offenses. Next, obligations of third parties to assist in exercising the right and do not impede this process. There are also obligations in relation to the rights holder. Some of them are feasible in the process of its exercising [2]. The correct execution of others is a prerequisite for acquiring the right. Naturally, occurrence of certain legal facts is not in accordance to the will of a legal entity concerned, for example termination of a certain age, which does not comply with specific obligation. The entity shall comply with the imperative requirement for its occurrence, following the required behavior, expressed in inaction.

In some cases, the ascertained right is accompanied with an obligation to its exercise. A place in this sequence also has obligations, stemming from the exercise of rights. Naturally, everyone solely judges of whether to exercise or not a right, but the normative commitment with a consequence of this process implies meeting the due behavior. In other words the achieved measure of freedom in some cases forms lack of freedom to the holder of that right. 
It is important to be accounted other group of obligations with belonging to another normative system. These are socalled "moral obligations", to which the law confers relevancy, without formally regulate them. Modern achievements of science and technology pose a number of questions, facing human societies for the liabilities in relation to the somatic rights. This makes indispensable reporting the accomplishments of bioethics at demarcation the borders in their development [3].

The legal norm in its essence has a mandatory character, naturally in the presence of legal facts, set by its hypothesis. This means that the subjective right, which is part of the contents of a legal rule, is accompanied with its compulsory. The legal norm, in turn, is part of the system of legal norms, constituting the normative system of law. Its essential function is order of magnitude, not of any kind, but compulsory [4]. Hence, also it implies the presence of normative commitment. Conditionally could be distinguished several groups of entities, covered by the legal commitment, in their quality as participants in a legally regulated public relations and connections. The first group includes entities, which are able to choose. If their choice is to enter in the legal regulated interaction, their behavior should be in compliance with the normative system of law. Thus, they implement required behavior and inconsistencies with it shall lead to negative consequences. They may prefer the opposite, without having a legal regulation for a negative result. The other group of entities doesn't have the same kind of choice. Obviously, to the first group of entities law provides subjective rights, while to the other - assigns legal obligations.

As seen, the normative system of law contains a number of requirements to the holder of the subjective right, implementation of which ensures the occurrence of desired legal consequences. Their precise execution is a guarantee of legitimacy of the subsequent interactions. Since his choice and voluntary inserting within the legal rule, he should synchronize his behavior with the law. Therefore, to that system of obligations, which form the "comfort" of a right, could also be added the mandatory nature of the legal rule, which places in normative commitment as well as the holder of this right and third parties. When a person is a carrier of a right, stemming from the existence of a valid legal norm and occurred legal facts, contained in its hypothesis, should be concluded that "others have the actual or hypothetical legal obligation to act or not to act in a particular way" [5]. From the foregoing follows another conclusion - the lack of validity for a legal rule means the absence of law and respectively absence of compulsoriness and obligation resulting from it.

\section{The obligations in the process of realization of rights}

At the same time a major emphasis in clarifying the essence of a right is the freedom, understood as an opportunity to implement or not to implement certain behavior, the ability be required or not to be required a particular behavior. This, in turn, means that whenever any of these obligations is not fulfilled, occurs inconsistencies between the content, incorporated by the legislature in the respective right in its institutionalization and the realization of the same right. Thus outlines the following working hypothesis - the right, understood as a legal measure of freedom, is being realized into the legal reality in boundaries, defined by the system of obligations and in this sense, it is dependent on their implementation. Or in other words, the behavior, that is in direct relation to freedom, is objectified into the legal reality in an autonomous 
sphere, defined by unfreedom /lack of freedom/?

The last implies the need of acting in particular manner. Compliance with defined rules means presence of an order, which is formed by them, and this, in turn, means the existence of correlation between the behavior of the addressees of these rules and their contents [6]. So, by a particular way of acting under certain circumstances is achieved consistency in the behavior of citizens [7]. This results in the attainment of an order, which is aggregation of desirable, predictable consequences. Essential role for further consistency is applying an integrated approach, especially within the European Union and in particular in the area of freedom, security and justice. In this sense is the following conclusion, relevant to increasing the efficiency of fulfillment of the obligation for protection of the rights established: "The legal integration in all matters of penal law is impossible and undesirable, because it would eliminate the possibility of Member States to consider what kind of needs has the particular civil society and how in the most effective way to protect the public relations with the means of the legislative activity." [8] Thus, the process of reflecting the needs of civil society in legislative activities as rights, freedoms and obligations, takes place within the area of freedom, security and justice. That is a zone, in which, in accordance with art. 67, pt. 1 of the Treaty on Functioning of the European Union are respected the fundamental rights and the different legal systems and traditions of the Member States.

\section{Formation of a personal legal sphere}

The autonomous legal sphere, within which is manifested the legal measure of freedom into the legal reality, is with fixed boundaries from the normative system of law. In this sense, the behavior, through which is realizing a right, should be in compliance with them.
They are "built" by restrictions. Limiting the parameters of this behavior, and hence of freedom is possible through the establishment of obligations. The objective of their existence in the legal system law is - individuals in their legally regulated interactions to achieve compliance with the requirement of legal equality [9]. Citizens in their capacity of entities of the law could be considered as a system, with a view to the orderliness of law. In this manner, every individual, except a holder of rights, is also a holder of obligations, which are intended to form an individual, autonomous legal sphere. Its outlines are formed by obligations, that lead to the existence of juridical boundaries between people, and by nature it is "... a sphere of freedom, provided by the law of each legal entity [10]." The consequence of this is mutual restriction of freedom between legal entities, through obligations, not only in relations among them, but in relations with the state, which makes possible the existence and exercise of rights.

\section{Positioning of boundaries}

Any amendment to position of these pre-established boundaries entails a change in the relation rights-freedom. The effect of any arbitrary change will be negative not only for the existence of rights, but may also lead to their degradation, and hence, negatively influencing the supported legal order in society. Therefore, every change, by setting obligations for a choice or a refrain from choosing a certain behavior, should be a consequence of legislative process that guarantees of accuracy. One of the possible solutions is to create an effective matrix of law creativity, following which will have the consequence for flexible legislative decisions and permanently improving the quality of legislation [11]. Moreover, the precision of obligations is relevant to any initial establishment of rights, as well as imperative or dispositive determined means for their realization. The 
process is extremely complex, regardless of the principle of attaining maximum opportunities, consistent with the current legislation, in the implementation of the respective right, which requires a minimum of restrictions, i.e. establishing minimum obligations of the abovementioned type. This is so, because it is of importance not only the procedure, but also their linguistic expression and accounting the role of non-legal evaluation phenomena such as justice, freedom, interest, purpose, etc., including analyzes of equality and non-discrimination. For example, a higher degree of concretization of the obligation for implementing a certain behavior narrows the perimeter of permitted behavior. This could be achieved with precision of the formulation and the higher degree of detailization. Of the other part, more generally formulated obligation implies an increase in options within the limits, determined by it. The obligation to refrain from a certain behavior could also be formulated in details or referring back. A consequence of this would be the limitation of a right to a lower or higher degree.

For some of the rights these limits are constant, others are subject to a change under certain circumstances, such as war or any other emergency circumstance, threatening the life of the nation. That possibility of amendment is defined at their initial institutionalization into the legal normative act, because exercising them in unaltered way will hamper not only the process, but also their protection and counteraction of circumstance of the abovementioned kind. Thus, through the change, by limiting them, the state not only guarantees the process of their exercise and protection, but uses the limitation as a tool to prevent and reduce the negative consequences, in case of threatening the existence of the nation.

\section{Conclusion}

Each right is placed into a system of legal obligations that determine the boundaries of its implementation in the legal reality. Their existence depends on the willingness of the right holder, of that of third parties and the state, and it is a consequence of their mutual respect. This mutual respect has another positive effect. It favors the building a community by citizens [12]. Of special importance in these relationships is the role of the State, which through legal regulation ensures the protection of rights and the realization of the so-called civil liberty[13].

\section{References}

[1] Cf. Vassilev, V. Theory of Management, Varna, 2013, p.74

[2] Cf. Dikov, L. Course in Bulgarian Civil Law, Volume I, General Part, Printing house. K. Ovcharov, S., 1940, p.130. Prof. Dikov defines these obligations as a legal condition for exercising a subjective right.

[3] Cf. Ganeva-Belova, G. Current Trends in the Protection of Human Rights, Classic Design, S., 2013, p. 48

[4] Cf. Kelsen, H. The Pure Doctrine of the Law, Yurispres, S., 1995, p. 45

[5] Cf. Dworkin, R. To relate to rights seriously, IK HS, S., 2003, p. 38

[6] Cf. Hayek, F. Law, Legislation and Liberty, Volume I, Legal norms and Rule of law, University Publishing House "St. Kliment Ohridski ", S., 1996, p. 128

[7] Cf. Fuller, L. The Morality of Law, Yale University Press, 1969, p. 39

[8] Cf. Marin, N. Jurisdiction of the European Court of Justice in the Area of Freedom, Security and Justice, University Publishing House "Neofit Rilsky", Blagoevgrad, 2011, pp.63-69

[9] Cf. Fries, Pilosophishe Rechtslehre, 1803, p.7. In that sense, it is the provision of Art.1 of the Universal Declaration of Human Rights and Art. 6, Para. 1 of the Constitution of the 
Republic of Bulgaria, according to the content of which, the freedom is inherent in every person from the moment of his birth, as well as the equality in dignity and rights.

[10] Cf. Del Vecchio, J. Fairness, Yurispres, C, 1995, p. 108

[11] Cf. Mihailov, G. Matrix of the Legislative Activity, Proceedings of Student Scientific Session-SNS `14, Law, Politics, Administration, 2014, p.7

[12] Cf. Kolev, T. Law and Right as a Cultural Phenomenon, Ciela, S., 2015, p. 2

[13] Cf. Habermas, J. Citizenship and National Identity. Between Facts and Norms, Cambridge, 1997, pp. 497-498.

\section{Bibliography}

Del Vecchio, J. Fairness, Yurispres, C, 1995, p. 108

Dikov, L. Course in Bulgarian Civil Law, Volume I, General Part, Printing house. K. Ovcharov, S., 1940, p.130

Dworkin, R. To relate to rights seriously, IK HS, S., 2003, p. 38

Fries, Pilosophishe Rechtslehre, 1803, p.7

Fuller, L. The Morality of Law, Yale University Press, 1969, p. 39

Ganeva-Belova, G. Current Trends in the Protection of Human Rights, Classic Design, S., 2013, p. 48

Habermas, J. Citizenship and National Identity. Between Facts and Norms, Cambridge, 1997, pp. 497-498

Hayek, F. Law, Legislation and Liberty, Volume I, Legal norms and Rule of Law, University Publishing House "St. Kliment Ohridski ", S., 1996, p. 128

Kelsen, H. The Pure Doctrine of the Law, Yurispres, S., 1995, p. 45

Kolev, T. Law and Right as a Cultural Phenomenon, Ciela, S., 2015, p. 21

Marin, N. Jurisdiction of the European Court of Justice in the Area of Freedom, Security and Justice, University Publishing House "Neofit Rilsky", Blagoevgrad, 2011, pp.63-69

Mihailov, G. Matrix of the Legislative Activity, Proceedings of Student Scientific SessionSNS `14, Law, Politics, Administration, 2014, p.7

Vassilev, V. Theory of Management, Varna, 2013, p.74 